\title{
Hydrodynamic Conditions of the Bakalskaya Spit Degradation (Western Crimea) over the Past 30 Years
}

\author{
B. V. Divinsky ${ }^{凶}$, R. D. Kosyan \\ Shirshov Institute of Oceanology, Russian Academy of Sciences, Moscow, Russian Federation \\ 凶ivin@ocean.ru
}

Purpose. The paper is aimed at studying the morphodynamic features of the Bakalskaya Spit evolution being influenced by the sea wind waves and swell, namely assessment of inter-annual variations in the alluvial (erosion) areas of the Bakalskaya Spit coastline, analysis of inter-annual variability of the wind wave parameters, determination of the surface wave characteristics (or a combination of a few ones) responsible for the processes of the bottom material erosion or accumulation in the coastal zone.

Methods and Results. Based on the analysis of satellite images for 1984-2016, the areas of the bottom material accumulation or erosion of the Bakalskaya Spit coastline were determined. Application of the spectral wave model permitted to obtain time series of the main parameters of wind waves and swell (significant wave heights and propagation directions) in the Bakalskaya Spit coastal zone with the $1 \mathrm{hr}$ time resolution for the period from 1984 to 2016. The characteristics of surface waves responsible for the coastline deformation were revealed using the discriminant analysis.

Conclusions. Analysis of satellite images of the spit made it possible to distinguish three periods in the history of the Bakalskaya spit evolution: 1985-1997, 1998-2007 and 2007-2016. The first period was characterized by relative stability. The strongest erosion took place in 1998; after that the alluvial and erosion cases alternated for 10 years weakly tending to general erosion that constituted the second period. The third one that began in 2007 can be defined as the period of spit degradation accompanied by the irreversible loss of beach material. The basic parameters conditioning hydrodynamics of the Bakalskaya Spit water area are: total duration of storms; mean and maximum values of significant heights of wind waves and swell. Statistical characteristics of the wind waves' parameters are of a fairly strong inter-annual variability. According to the mean and maximum indices, the wind waves directed close to the normal to the coastline (WSW and WNW) are the most developed. The applied discriminant analysis permitted to draw a statistically reliable conclusion that the direction of the final (mean annual) wave impact on the coastal zone, conditioning the processes of sand accumulation or erosion was set by the waves directed to $\mathrm{NNW}$, at that the swell contribution was dominant. The impact degree is determined by strong storms with the directions close to the normal to the coastline, namely, the WSW ones.

Keywords: mathematical modeling, MIKE 21 SW, wind waves, swell, Bakalskaya Spit, morphodynamics

Acknowledgements: the problem was formulated within the framework of the RSF project No. 20-1700060, the experimental data were analyzed thanks to the RFBR financial support (projects No. 19-0500041 and 19-45-230002). The results were analyzed within the framework of program No. 0149-20190014 and the RFBR project No. 18-05-80035.

For citation: Divinsky, B.V. and Kosyan, R.D., 2021. Hydrodynamic Conditions of the Bakalskaya Spit Degradation (Western Crimea) over the Past 30 Years. Physical Oceanography, [e-journal] 28(3), pp. 266-281. doi:10.22449/1573-160X-2021-3-266-281

DOI: $10.22449 / 1573-160 X-2021-3-266-281$

(C) B. V. Divinsky, R. D. Kosyan, 2021

(C) Physical Oceanography, 2021

\section{Introduction and Task Setting}

The Bakalskaya Spit is an accumulative sandy form of $\sim 8 \mathrm{~km}$ length on the southern coast of the Karnitsky Bay of the Black Sea (Fig. 1). In 2000, the spit became part of the Bakalskaya Spit Landscape and Recreational Park occupying 
the area of 1550 hectares, securing the status of a unique natural object. Given this history of the Bakalskaya Spit development over the past 30 years, it can be called dramatic. Against the background of the general depletion of the beach material, the isthmus connecting the mainland with the northern end was eroded several times, then restored, until in 2010 it was totally separated, forming an isolated island [1].

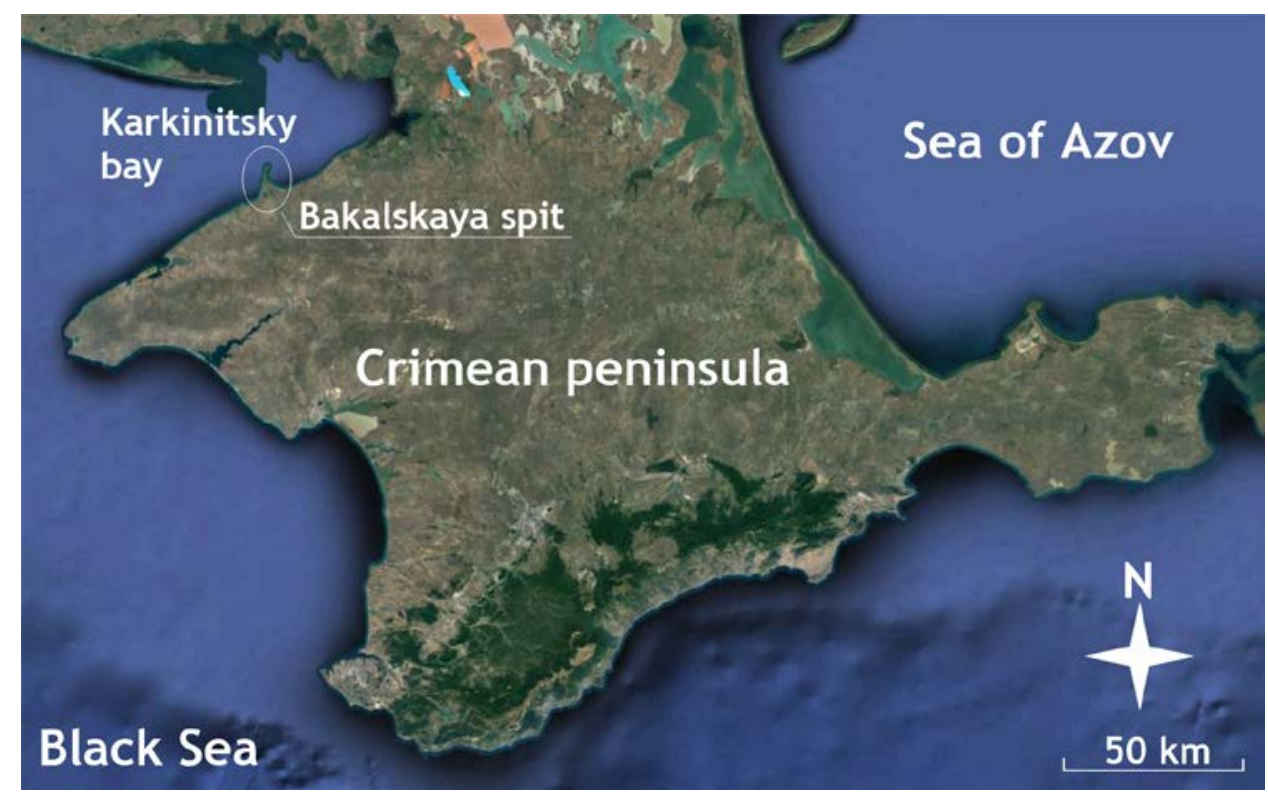

F i g. 1. Geographical position of the Bakalskaya Spit

In recent years, research on the Bakalskaya Spit problems has been significantly intensified. Below we highlight several main, in our opinion, publications concerning the hydrodynamic aspects of the spit reshaping and briefly focus on the main research results.

In [2], based on the analysis of satellite images for 1986-2009. The displacement speed of the western part of the spit into the Karkinitsky Bay was estimated, and amounted to $13 \mathrm{~m}$ /year. During the specified period, the absolute value of the displacement reached $300 \mathrm{~m}$. It is also shown that the general tendency of the spit development is determined by the processes caused by the increasing frequency of the western and southwestern winds with a significant decrease in the frequency of winds of the northwestern and northern points (in other words, the wind and wave direction are not the same). As a factor that caused the separation of its distal part from the Bakalskaya Spit, it is called "anomalously high sea level during this period" [2, p. 14], but this statement is not supported by arguments.

Taking into account that sea level is an important hydrodynamic factor of impact on the coastal zone, the authors of [3] studied the effect of storm surges on the processes of bottom material erosion and accumulation in the Bakalskaya Spit 
area. It is concluded that, depending on the wave direction, surges can lead to both intensification and weakening of erosion processes.

In [4], sediment flows in the coastal zone of the Bakalskaya Spit were studied, and the picture of the separation of the distal part of the spit from the main body under the conditions of individual extreme storms was modeled. It should be noted that in 2018 a specialized issue of the Environmental Safety of the Coastal and Shelf Zones of the Sea journal, entirely devoted to the experimental studies of the Bakalskaya Spit in 2017 and 2018, was published by the staff of Shirshov Institute of Oceanology and Marine Hydrophysical Institute RAS. Based on these studies, various aspects of the current state of the spit were analyzed in the works published in the special issue of the journal.

Climatic characteristics of wind waves in the Bakalskaya Spit water area as the main factor affecting the coastal zone have not been practically studied. Some related studies [5-8] are of a limited nature (for example, they are based on visual observations of sea waves, consider specific storm situations, or are referred to points of the western coast remote from the spit).

It is obvious that a retrospective assessment of the development of any coastline requires knowledge of the climatic characteristics of hydrodynamic parameters that affect morphodynamic processes. Based on this, the following tasks of the present paper are defined:

- to estimate the interannual variations in the areas of alluvial (erosion) of the coastline of the Bakalskaya spit;

- to study the interannual variability of the parameters of wind waves, while dividing the surface waves into components (wind waves and swell);

- to identify the characteristics of surface waves (or a combination of several ones), responsible for the processes of erosion or accumulation of bottom material in the coastal zone.

Earlier, the analysis of climatic variability of the main parameters of mixed (without separation) waves in the Bakalskaya Spit area was carried out in [9]. Importance of a separate consideration of wind waves and swell is associated with the fact that the effect of the wave components on the underwater slope being eroded is different. As a rule, the heights of wind waves are 2-3 times higher than the heights of swell ones. Collapse of wind waves leads to an increase in the transverse transport of bottom material with the formation (transformation) of underwater bars and the removal of material towards the sea. The swell dissipates in the near-water zone and contributes to the accumulation of sediments. For example, under the conditions of the Anapa bay bar [10], the contribution of swell to alongshore flows of bottom material can be up to $50 \%$, largely determining the processes of erosion or accumulation of beach-forming material along the coastline.

\section{Materials and Methods}

\section{Analysis of the spit morphodynamics}

Previous studies represent the Bakalskaya Spit development over the past few decades. What can act as a characteristic parameter of the spit transformation? It seems that such a parameter can be its area, speaking more precisely, not the area itself, but the ratio (or difference) of the areas in different years of observation. 
To estimate the areas, we will use satellite images posted in the Timelapse service on the Google Earth platform (https://earthengine.google.com/timelapse), allowing to trace the transformation of the coastline in the Bakalskaya Spit area from 1984 to 2016 (Fig. 2, b) gives an idea of what is meant by the area of the spit: it is the area of a figure bounded by a static (unchanging) southern boundary and a dynamic coastline.

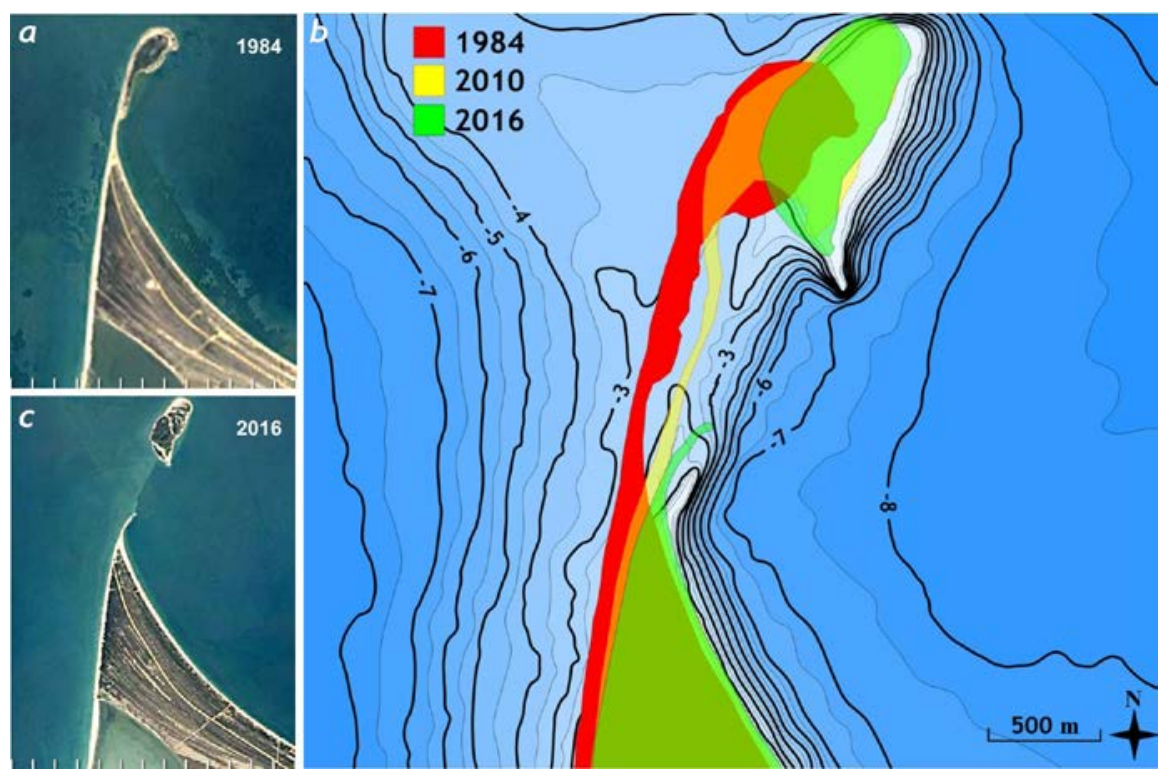

F i g. 2. Satellite maps of the Bakalskaya Spit for 1984 (a) and 2016 (c), and the examples of the spit calculated areas $(b)$. The depth on the map is given in meters

Note that the accuracy of the coastal edge determining depends on many factors: sea level, the current state of the atmosphere, digital properties of images, etc. Since in the future we will be interested not in the absolute marks of the coastline position, but in the difference between the its positions in adjacent years, then, in our opinion, the advantage is the same method of finding the coastline, applied to all images. In other words, the same nature of errors arising when fixing the coastline position using satellite images for each year is assumed. In this case, of course, general errors are inevitable, the minimization of which is possible by improving the quality of the original images.

The depth map was built based on the data from expeditionary studies of the Institute of Oceanology carried out in 2018 [11] and refined in 2019 [12]. Note that to date, this is the most detailed map of the area. Attention is drawn to a characteristic detail of the underwater relief: a relatively shallow western part with an extensive underwater bank in the northwestern part and a sharp drop in depths to the east of the spit.

Fig. 2, $b$ gives a clear idea of the general picture of the spit degradation: 1) the distal part displacement in the eastern direction has been $\sim 300 \mathrm{~m}$ since 1984 ; 2) the spit displacement in shallow water with a change in the wave regime allowed it to recover; 3 ) reaching the edge of the canyon led to irreversible loss of 
sand. The sand transfer from the western part of the water area to the eastern one is indirectly confirmed by the granulometric analysis of bottom sediments.

In order to analyze the granulometric composition of sediments, in June 2019 samples were taken (Fig. 3). Sorting of sand by size is described in terms of the lognormal distribution of particle diameters $d$ with a distribution function in the form

$$
F(d)=0,5\left[1+\operatorname{erf}\left(\frac{\log \left(\frac{d}{d_{50}}\right)}{\sqrt{2} \log \sigma_{d}}\right)\right],
$$

where erf is the error function; $d_{50}$ is the median particle size; $\sigma_{d}$ - geometric standard deviation, defined as $\left(d_{84} / d_{16}\right)^{0,5}$.

Features of the granulometric composition of bottom sediments are shown in Fig. 3. Soil samples were taken in the near-water part of the spit from the western (point 1 in Fig. 3, b) and eastern (point 3) sides, as well as directly to the cape (point 2). As follows from Fig. 3, in the western part of the spit adjacent to the strait, the median diameter of sand particles is significantly larger than that in the eastern part. Directly in the strait itself (point 2), the grain size distribution curve is characterized by a multimodal distribution, which indicates the intensity of the processes of entrainment and processing of bottom sediments. These features may indicate that the main mechanism of sand transport in the strait area is the erosion of the western part of the spit head and the processed material transfer to its eastern part.

The aforementioned considerations indicate an important detail: the transfer of sand along the western part of the spit until 2010 (i.e., until the moment of the final breakthrough of the isthmus) could have been reversible; after the breakthrough, part of the bottom sediments began to irretrievably go to the eastern part.

Thus, when calculating the areas of the spit, the position of the coastline is assumed to reflect the most general (integral) processes of erosion or accumulation of bottom material under the influence of wind waves.

Parameters of the wind waves

A modern and effective tool for studying the parameters of surface waves is mathematical modeling. It allows calculating the parameters of sea waves for any period of time using the initial wind fields. In the present paper, the modern spectral model DHI MIKE SW ${ }^{1}$, being successfully used both for open water areas and in the coastal zone, is used.

${ }^{1}$ DHI, 2007. MIKE 21. Spectral Wave Module: Scientific documentation. Hørsholm, Denmark: DHI, 56 p. Available at: https://manuals.mikepoweredbydhi.help/2017/Coast_and_Sea/M21SW_Scientific_Doc.pdf [Accessed: 30 April 2021]. 
The model fully implements the stages of nucleation, attenuation and transformation of wind wave fields, taking into account the following physical mechanisms:
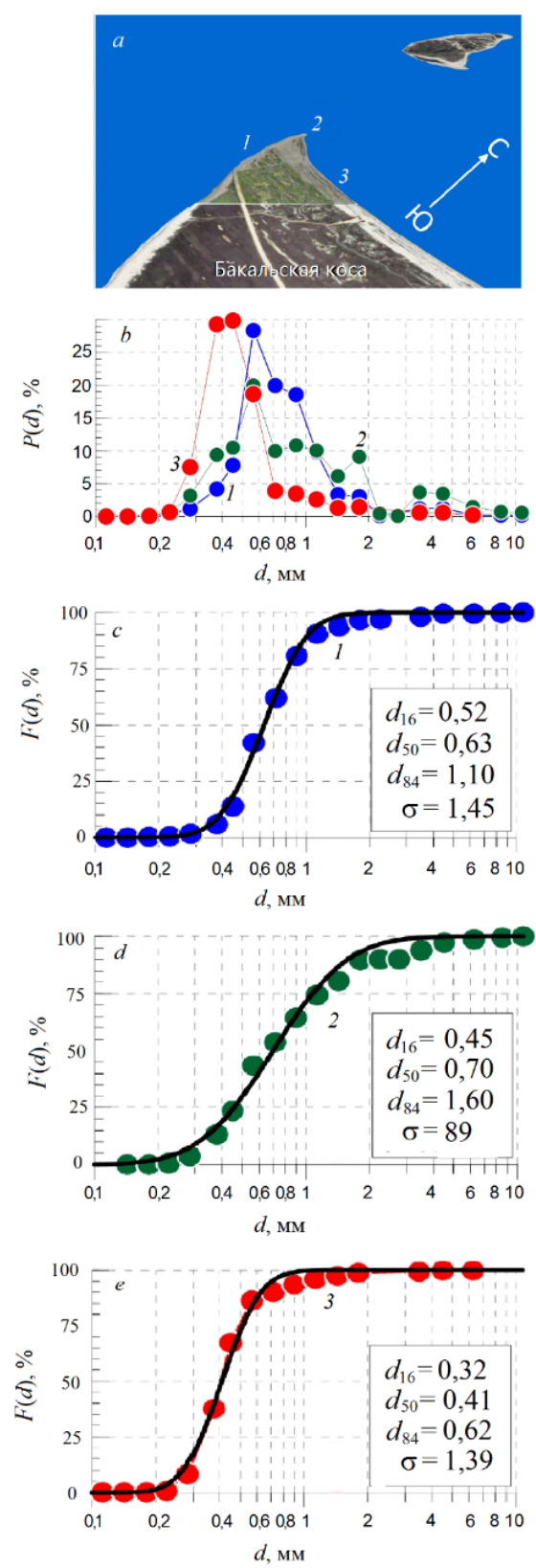

F i g. 3. Points of bottom sampling (a), curves of granulumetric composition $(b)$ and functions of the sand particle size distribution corresponding to the samples taken at the points of the bottom sampling: $1(c) ; 2(d) ; 3(e)$
- refraction of wave rays in the field of variable bathymetry and currents;

- diffraction (approximately);

- blocking and reflecting waves in the opposite direction;

- dissipation of wave energy due to bottom friction, collapse and whitecapping;

- three and four wave interactions.

The model input parameters are the east and north components of the surface wind obtained from the ERA-Interim analysis. The initial wind fields cover the Black Sea with a spatial resolution in latitude and longitude of $0.25^{\circ}$. The temporal discreteness of the fields is 3 hours. Earlier, the model was successfully verified for the Black Sea conditions [13] and adjusted to automatically separate the surface wave parameters into two components: wind waves and swell [14].

As a result of the calculations, time series of the main parameters of wind waves and swell in the coastal zone of the Bakalskaya Spit were obtained: significant wave heights, propagation directions - for 19842016 with a time discreteness of 1 hour. The calculated point is located to the west of the central part of the spit at a depth of $10 \mathrm{~m}$. 


\section{The Research Results}

Any analysis, as a rule, is limited by some conventions and uncertainties. In the present case, this applies primarily to the areas of the spit obtained by processing satellite images. Unfortunately, the task of determining the date of the photographs turned out to be very difficult. Indirectly, it was possible to establish that a third of 32 images (from 1984 to 2016) of the Bakalskaya Spit surface were taken in the summer months. As an assumption, it is assumed that all surface images are dated in the summer of the corresponding year. Of course, there may be doubts about the validity of such assumptions, but we hope that the approach described in the work will be useful in the case of clarifying the initial data.

In addition, the data on the wave regime, determined only for the western part of the water area adjacent to the Bakalskaya Spit, are analyzed. This is due to two circumstances: 1) the values of all parameters of storm situations in the western part are much higher than in the eastern [9], so that the general dynamics of the spit is almost completely determined by the processes occurring in the western part of the water area; 2) the attraction of additional parameters in this case only complicates the analysis.

First, the area of the spit for 1984-2016 is calculated: $S_{1984}, S_{1985}, \ldots, S_{2016}$. The differences in areas in adjacent years are found, e.g. $\Delta S=S_{1985}-S_{1984}$. It is supposed that $\Delta S$ corresponds to the increase (or decrease) in the beach area from September 1984 to May 1985 (summer months for the reasons stated above are not taken into account). For the same period (from September 1984 to May 1985), the statistical characteristics of waves were calculated. Thus, in the expression, as "the maximum height of significant waves in 1985" under the words "1985" a time period including nine months is understood: the autumn months of 1984, as well as the winter and spring months of 1985. Similar calculations were also carried out for all adjacent years.

In addition to the difference in areas, to illustrate the general trends in the spit development over the past 30 years, the spit area ratio for each year from this range to its area in 1984 was calculated (Fig. 4).

As follows from Fig. 4, $a$, in the history of the Bakalskaya Spit development over the past 30 years, three periods can be distinguished: 1985-1997, 1998-2007 and 2007-2016. The first period is a period of relative stability, the second is characterized by alternating cases of alluvial and erosion with a weak tendency towards general erosion and the third is a period of degradation, accompanied by an irreversible loss of beach material. Really extreme erosion was observed in 1996 and 1998. (Fig. 4, b). In 1997, after the catastrophic erosion of 1996, the beach not only recovered, but also significantly increased in area. Significant erosion was also recorded in 1990 and 2015. The reasons for the erosion (accumulation) of the beach material naturally lie in the peculiarities of the hydrodynamic regime of a particular year.

The following parameters are chosen as the main ones determining the hydrodynamics of the water area of the Bakalskaya Spit:

- the total duration of storms;

- mean and maximum significant heights of wind waves and swell. 


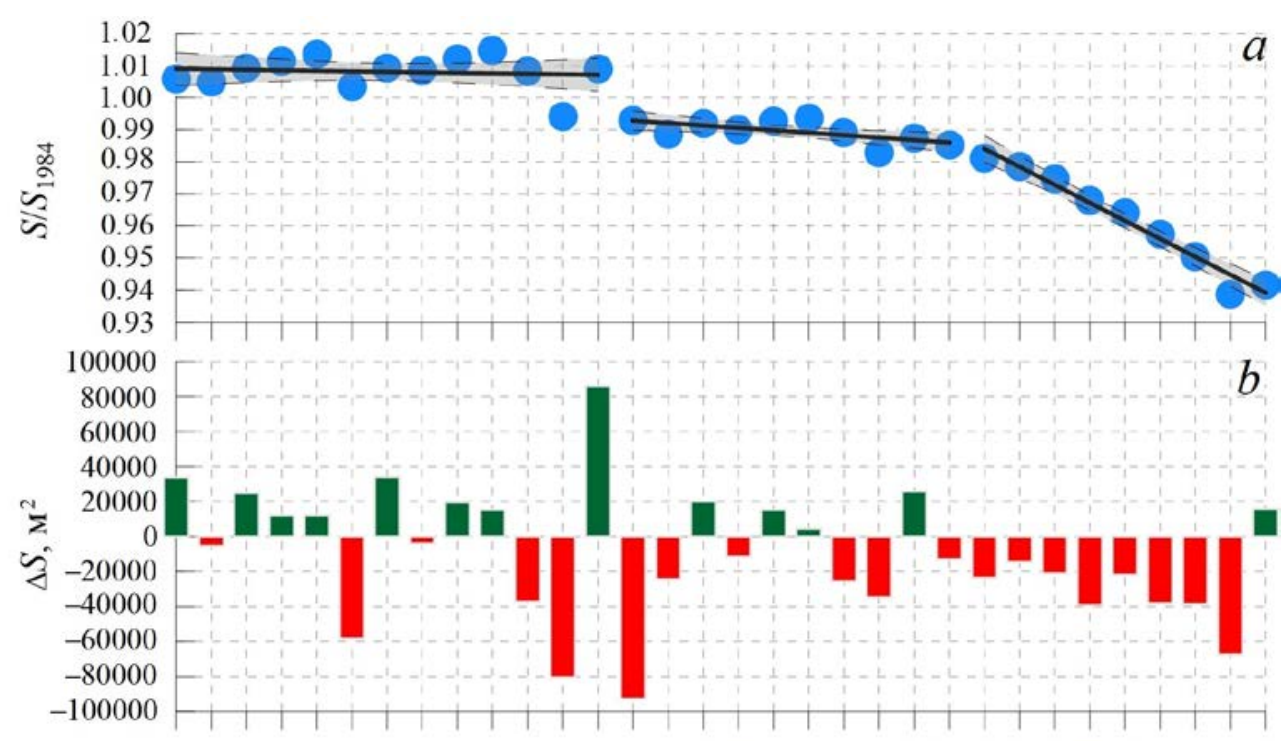

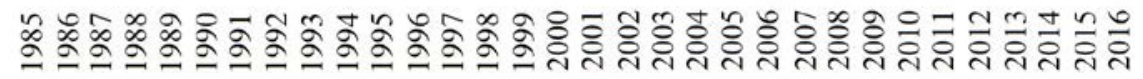

F i g. 4. Morphodynamic characteristics of the Bakalskaya Spit evolution: $a$-the ratio of the spit area in a given year to its area in 1984; $b$ - area differences between the neighbouring years

The transport of bottom sediments (lateral and alongshore) largely depends on the angle of approach of storm waves to the coast. For the sector of the western water area, four 45-degree wave sectors relative to the general direction of the coast are singled out (Fig. 5, b). Two of them (WSW and WNW) are close to the normal to the coast, two (SSW and NNW) define an oblique wave traverse. In future, all statistical characteristics of the waves will be divided into these sectors. Fig. 5, $a$ shows the total duration of storms in four sectors of waves.
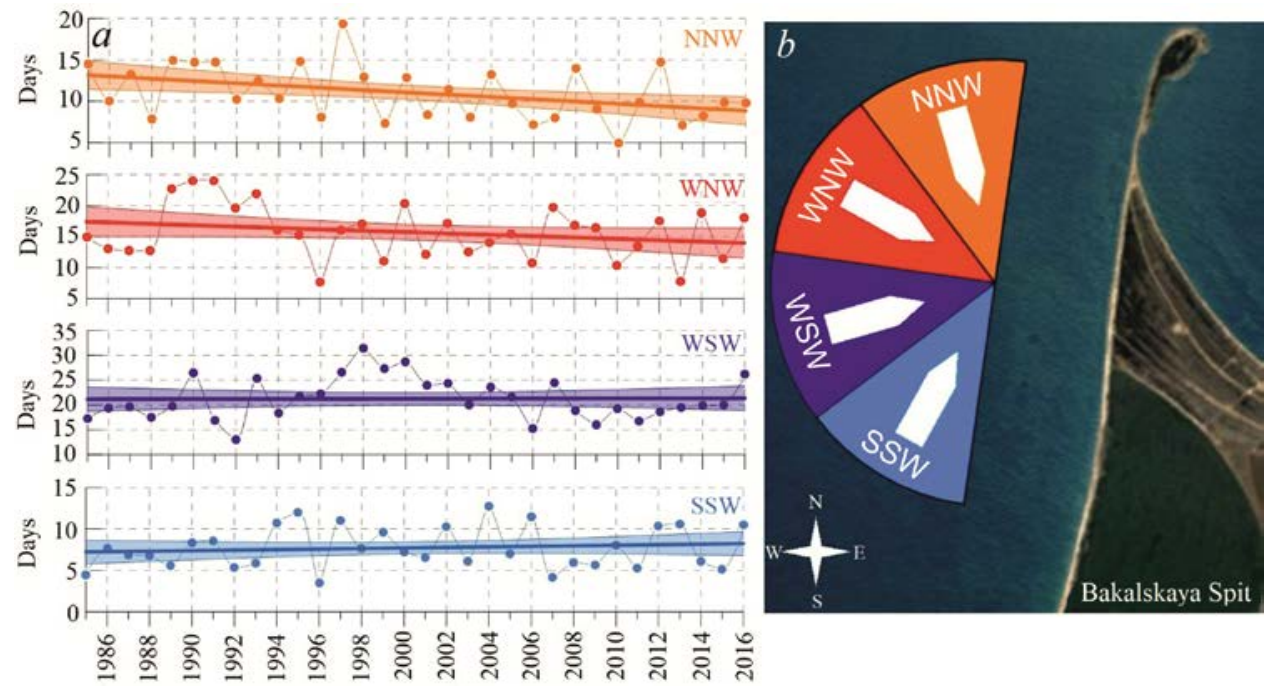

F i g. 5. Storm durations by the wave sectors (a) selected according to the scheme (b)

PHYSICAL OCEANOGRAPHY VOL. 28 ISS. 3 (2021) 
It should be specified that: by the beginning of a storm the excess of the curve of the mixed wave power variation equal to $1 \mathrm{~kW} / \mathrm{m}$, corresponding to a significant wave height $\sim 0.65 \mathrm{~m}$ is meant. Of course, the choice of the threshold level is largely controversial, but in the present case, firstly, it is important to apply one rule to all sectors that are too different in storm activity, and, secondly, it is desirable to obtain a significant number of storms.

The statistical characteristics (mean and maximum) of significant wave heights obtained, recall, for 9-month time intervals, as well as the corresponding linear trends and $90 \%$ confidence intervals are shown in Fig. 6.
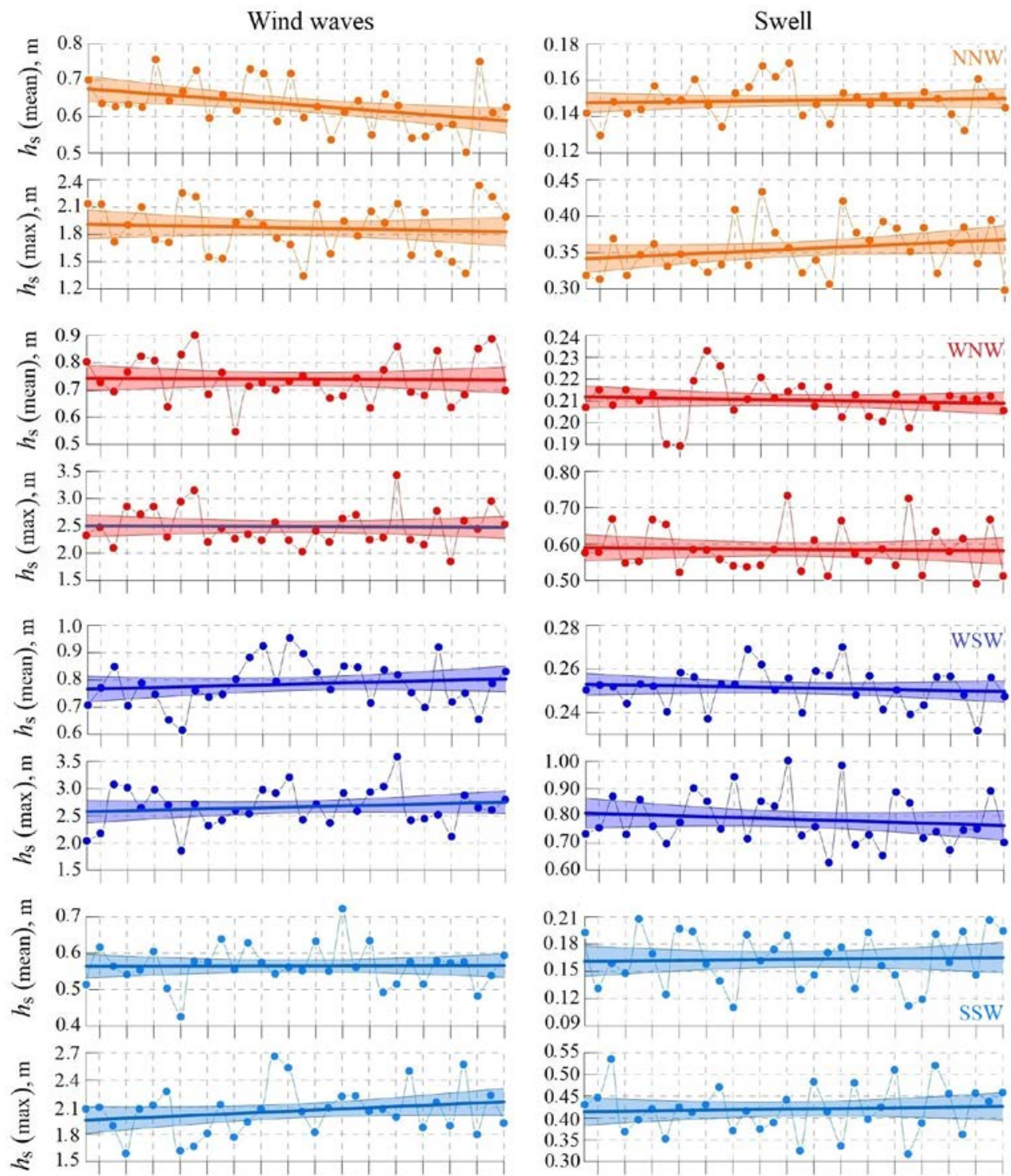

œ

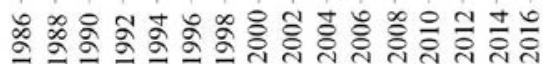

F i g. 6. Mean and maximum significant heights (m) of wind waves and swell by the wave sectors (see Fig. 5, $b$ ) 
So, as a result of the studies carried out, the interannual areas of erosion (alluvials) of the beach zone of the Bakalskaya Spit were determined, as well as some hydrodynamic parameters characterizing the effect of surface waves on the coastal zone. It should also be noted that the statistics of storms are very evaluative, since a storm can start to develop in one sector and decay in another.

\section{Results and Discussion}

First, a general description of the wave regime in the western part of the Bakalskaya Spit water is given:

- storms of the southwest directions are characterized by the longest duration (Fig. 6); on mean, the storms of these points last for 22 days. Storms in WNW directions are somewhat shorter. In general, storms with directions close to the normal to the coastline (ESW and WSW) prevail in the annual cycle. The characteristic mean annual duration of a storm in the SSW directions is about a week, NNW -11 days;

- the statistical characteristics of the heights of sea waves experience a fairly strong interannual variability. According to the mean and maximum indicators, the most developed are wind waves with directions close to the normal (ESW and WSW). SSW wind waves are the weakest on mean, but strong storms in these directions can be accompanied by waves exceeding $2.5 \mathrm{~m}$;

- the heights of swell waves, as a rule, are 2-3 times less than the heights of wind waves, however, in some years, swell with heights of significant waves $\sim 1 \mathrm{~m}$ (WSW directions) can be observed.

We admit that for the analysis of the coastline alluvium - erosion processes, the graphs of the interannual variability of the wave parameters are not very informative, the general trends of the impact (if any) are subtle.

For example, the strongest alluvium in 1997 (see Fig. 4) took place against the background of the longest NW directions ever during storm observations (see Fig. 5); in 1998, the disturbance of the SSW points continued for more than a month and (possibly!) led to extreme erosion. However, these details are not in the nature of patterns.

So, the areas of interannual alluvials or erosion forming the body of the Bakalskaya spit were estimated. The coastline position is determined by a combination of many factors: lithodynamic (granulometric composition of sediments), bathymetric (changes in depths and local slopes of the bottom) and hydrodynamic (waves, currents, sea level). Of all the above, we have only data on the mode of wind waves obtained by a model. Let us put a question: is it possible to determine the characteristics of surface waves that are most responsible for the coastline deformation processes in mean annual terms? Here we mean a general (integral) estimate for the entire spit, since it is obvious that a storm of a certain direction can erode one part of the spit and move sand to another part, defining a local alluvium in it, so that the total losses in this case will be almost zero.

We will try to answer this question by means of discriminant analysis a section of multivariate statistical analysis that allows determining the belonging of objects to non-overlapping and initially specified classes (groups). 
Perhaps there is no need to give all the details of the discriminant analysis procedures, an excellent overview of which is presented in [15]. The analysis was carried out in the Statistica software environment.

The main idea of discriminant analysis is to construct special functions composed of linear combinations of features with their own coefficients (contributions). With the help of discriminant functions (DF), it is possible to assess the reliability of intergroup differences, as well as to find the signs that primarily determine intergroup differences.

Three conditions for the transformation of the beach, which characterize the hydrodynamic response depending on the magnitude of the alluvium - erosion are determined:

- when $\Delta S>5000 \mathrm{~m}^{2}$ the alluvium of the beach area occurs;

- when $\Delta S<-5000 \mathrm{~m}^{2}$ - the erosion;

- when $-5000 \mathrm{~m}^{2}<\Delta S<5000 \mathrm{~m}^{2}$ - minor changes.

The discriminant variables are the mean annual and maximum (for a conditional year) significant wave heights of separate wind waves and swell for each of the four wave sectors, a total of 16 parameters (Table 1).

In what follows, for convenience, we will adhere to the following notations: SSW- $h_{\mathrm{w}}($ mean) - mean height of the wind waves in SSW wave sector, WSW- $h_{s}(\max )$ - maximum height of swell in WSW sector, etc. Note also that 32 data rows corresponding to the years from 1985 to 2016 will be called observations.

Table 1

Discriminant groups and variables

\begin{tabular}{|c|c|c|c|c|c|c|c|c|c|c|}
\hline \multirow{3}{*}{ Year } & \multirow{3}{*}{$\Delta S, \mathrm{~m}^{2}$} & \multirow{3}{*}{ Group } & \multicolumn{8}{|c|}{ Discriminant variables for a wave sector } \\
\hline & & & \multicolumn{4}{|c|}{ SSW } & \multicolumn{4}{|c|}{ WSW } \\
\hline & & & 1 & 2 & 3 & 4 & 1 & 2 & 3 & 4 \\
\hline 1985 & 33854 & Alluvial & 0.51 & 2.08 & 0.19 & 0.43 & 0.71 & 2.04 & 0.25 & 0.73 \\
\hline 1986 & -5425 & $\begin{array}{c}\text { Insignificant } \\
\text { changes }\end{array}$ & 0.62 & 2.10 & 0.13 & 0.45 & 0.77 & 2.18 & 0.25 & 0.76 \\
\hline 1987 & 24826 & Alluvial & 0.56 & 1.89 & 0.16 & 0.54 & 0.85 & 3.07 & 0.25 & 0.87 \\
\hline 2014 & -38773 & Erosion & 0.48 & 1.80 & 0.15 & 0.46 & 0.65 & 2.65 & 0.23 & 0.75 \\
\hline 2015 & -67455 & Erosion & 0.54 & 2.23 & 0.21 & 0.44 & 0.79 & 2.61 & 0.26 & 0.89 \\
\hline 2016 & 15895 & Alluvial & 0.59 & 1.92 & 0.19 & 0.46 & 0.83 & 2.80 & 0.25 & 0.70 \\
\hline
\end{tabular}

Continuation of Table 1

\begin{tabular}{|c|c|c|c|c|c|c|c|c|c|c|}
\hline \multirow{3}{*}{ Year } & \multirow{3}{*}{$\Delta S, \mathrm{~m}^{2}$} & \multirow{3}{*}{ Group } & \multicolumn{8}{|c|}{ Discriminant variables for a wave sector } \\
\hline & & & \multicolumn{4}{|c|}{ SSW } & \multicolumn{4}{|c|}{ WSW } \\
\hline & & & 1 & 2 & 3 & 4 & 1 & 2 & 3 & 4 \\
\hline 1985 & 33854 & Alluvial & 0.80 & 2.33 & 0.21 & 0.58 & 0.70 & 2.14 & 0.14 & 0.32 \\
\hline 1986 & -5425 & Insignificant changes & 0.73 & 2.47 & 0.22 & 0.58 & 0.64 & 2.13 & 0.13 & 0.31 \\
\hline 1987 & 24826 & Alluvial & 0.70 & 2.10 & 0.21 & 0.67 & 0.63 & 1.72 & 0.15 & 0.37 \\
\hline 2014 & -38773 & Erosion & 0.85 & 2.45 & 0.21 & 0.49 & 0.75 & 2.34 & 0.16 & 0.34 \\
\hline 2015 & -67455 & Erosion & 0.89 & 2.95 & 0.21 & 0.67 & 0.61 & 2.22 & 0.15 & 0.39 \\
\hline 2016 & 15895 & Alluvial & 0.70 & 2.52 & 0.21 & 0.51 & 0.63 & 2.00 & 0.15 & 0.30 \\
\hline
\end{tabular}

$\mathrm{N}$ o t e: 1 - mean height of wind waves; 2 - maximum height of wind waves; 3 - mean height of swell; 4 - maximum height of swell 
The task of the present paper is to obtain DFs that are a linear combination of all variables. The weights of the variables will determine the contribution of these variables to the discriminating ability of the function. In this case, two DFs (one less than the number of groups) should be found.

At the first stage of the analysis, a very useful procedure is to reduce the number of initial features (variables). Use of the method of sequential inclusion of variables in the model made it possible to determine the parameters that make the least contribution to intergroup differences. Features excluded from the model are WSW- $h_{\mathrm{w}}(\operatorname{mean}) ; \mathrm{WSW}-h_{\mathrm{s}}(\max ) ; \mathrm{WNW}-h_{\mathrm{w}}(\max )$ and NNW- $h_{\mathrm{w}}($ mean).

To estimate how the remaining 12 variables share the 3 selected groups, two DFs were calculated (Table 2). Table 2 shows that $\mathrm{DF}_{1}$ is responsible for almost $85 \%$ of the explained variance, that is, $85 \%$ of all discriminating power is determined by this function. $\mathrm{DF}_{2}$ accounts for $15 \%$ of the variance.

Table 2

Characteristics of the discriminant functions (DF)

\begin{tabular}{c|c|c|c|c|c}
\hline $\mathrm{DF}$ & Eigevalue & $\begin{array}{c}\text { Contribution to } \\
\text { dispersion, } \%\end{array}$ & $\begin{array}{c}\text { Canonical } \\
\text { correlation }\end{array}$ & $\Lambda$-statistics & $p$-value \\
\hline $\mathrm{DF}_{1}$ & 5.57 & 84.9 & 0.92 & 0.0760 & 0.000053 \\
$\mathrm{DF}_{2}$ & 0.99 & 15.1 & 0.71 & 0.5013 & 0.132914 \\
\hline
\end{tabular}

The canonical correlation coefficient serves as an indicator of the separative power of the DF. A high coefficient for the first DF indicates a strong relationship between variables and groups. The $\Lambda$-statistic shows whether the mean values of DF differ significantly in the two groups. Small values of the $\Lambda$-statistic (around 0 ) indicate that the mean values of the groups differ. In addition, for the first DF, the significance level $p$ is less than 0.05 , i.e., the difference is significant.

Table 3

\section{Standardized regression coefficients and canonical correlations for the discriminant functions and variables}

\begin{tabular}{|c|c|c|c|c|}
\hline \multirow{2}{*}{ Discriminant variable } & \multicolumn{2}{|c|}{ Standardized coefficients } & \multicolumn{2}{|c|}{ Canonical correlation } \\
\hline & $\mathrm{DF}_{1}$ & $\mathrm{DF}_{2}$ & $\mathrm{DF}_{1}$ & $\mathrm{DF}_{2}$ \\
\hline$N N W-h_{s}(\max )$ & -1.971 & 0.039 & -0.613 & 0.106 \\
\hline$W S W-h_{w}(\max )$ & 0.665 & 1.463 & -0.079 & 0.509 \\
\hline WSW- $h_{\mathrm{s}}($ mean $)$ & 1.056 & -1.284 & 0.067 & -0.233 \\
\hline SSW- $h_{\mathrm{w}}$ (mean) & -1.267 & 0.961 & -0.003 & 0.219 \\
\hline $\mathrm{WNW}-h_{\mathrm{w}}($ mean $)$ & -1.211 & -0.290 & -0.015 & -0.027 \\
\hline $\mathrm{NNW}-h_{\mathrm{w}}(\max )$ & 1.468 & -0.146 & 0.119 & -0.046 \\
\hline$S S W-h_{s}($ mean $)$ & 0.727 & 0.767 & 0.144 & 0.103 \\
\hline$W N W-h_{s}(\max )$ & 1.351 & 0.333 & -0.131 & 0.251 \\
\hline$S S W-h_{w}(\max )$ & -0.626 & -0.630 & -0.150 & 0.023 \\
\hline WNW- $h_{\mathrm{s}}($ mean $)$ & 0.848 & -0.095 & -0.030 & 0.101 \\
\hline$N N W-h_{s}($ mean $)$ & -0.442 & 0.638 & -0.078 & 0.354 \\
\hline$S S W-h_{s}(\max )$ & -0.449 & 0.051 & 0.052 & -0.004 \\
\hline
\end{tabular}


Contribution of variables to the discriminant function value is shown by the standardized coefficients. They permit to assess the relative importance of each discriminant variable when dividing the study groups. Canonical correlations show the strength of the relationship between discriminant variables and standardized DF values. Standardized coefficients and canonical correlations for all discriminant variables are presented in Table. 3.

Table 3 data show that the greatest contribution to $\mathrm{DF}_{1}$ is made by the extreme swell and wind waves of the NNW directions, in $\mathrm{DF}_{2}$ - the maximum wind waves and the mean swell of the WSW points. The highest correlation with DF is shown by $N N W-h_{s}(\max )\left(\mathrm{DF}_{1}\right)$ and $\mathrm{WSW}-h_{\mathrm{w}}(\max )\left(\mathrm{DF}_{2}\right)$.

The results of dividing observations into groups are presented by the scatter diagram (Fig. 7). The crosses in Fig. 7 shows the centroids corresponding to the mean DF values in the studied groups (i.e., typical observations of the corresponding class). The degree of separation of the studied groups characterizes the distance between the centroids of these groups. From Fig. 7 it follows that $\mathrm{DF}_{1}$ quite successfully separates the "erosion" and "alluvial” groups. $\mathrm{DF}_{2}$, despite the lack of statistical reliability, shares a minor and very significant storm impact on the coastline. In other words, $\mathrm{DF}_{1}$ determines the sign (direction) of the impact, $\mathrm{DF}_{2}$ - its strength.

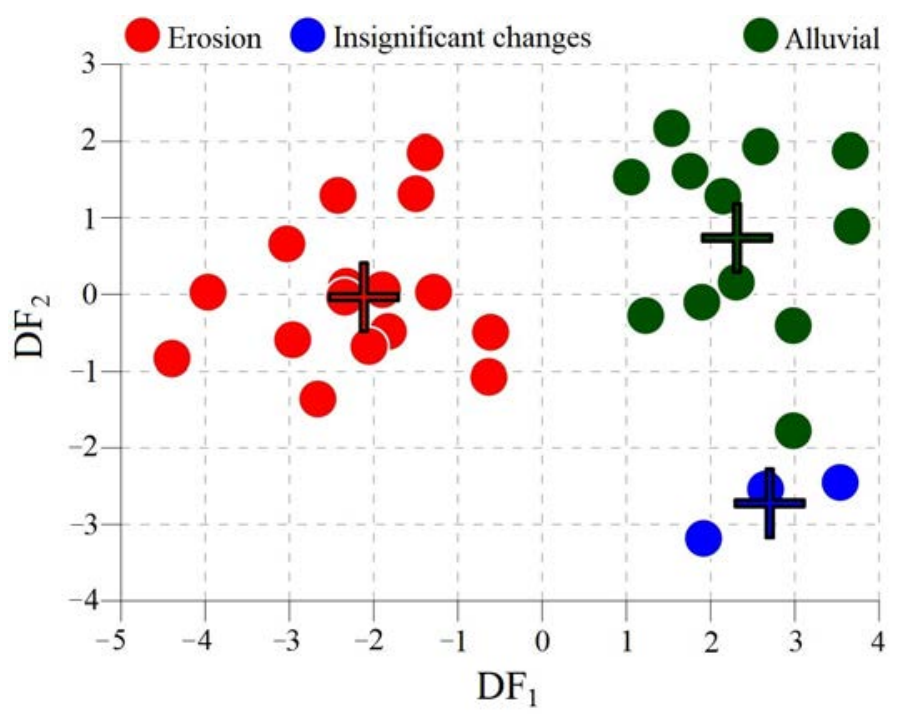

F i g. 7. Distribution of observations in the field of the discriminant functions

As it was mentioned above, the greatest contribution to $\mathrm{DF}_{1}$ is made by extreme swell and wind waves in the NNW directions, and the swell contribution prevails; in $\mathrm{DF}_{2}$ - the maximum wind waves and the mean swell of the WSW points. Thus, it can be concluded that the NNW waves, especially swell, determine the direction (in other words, the sign) of the total mean annual wave impact on the coastal zone, i.e., it determines whether it will be sand alluvial or erosion. The extreme wind waves of the WSW points and the background (mean) swell indicators in the same direction determine the force of the impact on the coastal zone. 


\section{Conclusion}

In the present paper, the interannual variations in the areas of alluvials (erosion) of the Bakalskaya Spit coastline are estimated. An attempt to identify the characteristics of surface waves (or a combination of several) responsible for the processes of erosion or accumulation of bottom material in the coastal zone was also made.

Analysis of satellite images of the spit permitted to distinguish three periods in the history of the Bakalskaya Spit development: 1985-1997, 1998-2007 and 2007-2016. The first period is a period of relative stability. In 1998, the strongest erosion occurred, after which, for 10 years, cases of alluvial and erosion alternated with a weak tendency towards general erosion. In 2007, the third period began, which can be defined as the period of degradation of the spit, accompanied by the irreversible loss of beach material.

Complex nature of the hydrodynamic impact complicates the identification of individual parameters of surface waves that are unambiguously responsible for the processes of erosion or accumulation of bottom material in the coastal zone. Nevertheless, the use of discriminant analysis made it possible to conclude with high statistical reliability that the direction of the final (mean annual) wave impact on the coastal zone, determining the processes occurring in it (erosion or accumulation of sand), is set by the excitement of the NNW directions, with the swell contribution prevailing. The severity of the impact is determined by strong storms with directions close to the normal to the coastline, namely the WSW.

It is obvious that studies were carried out with a number of inevitable assumptions; nevertheless, we believe that their results correspond to the general concepts of morphodynamic processes in the coastal zone of the sea.

\section{REFERENCES}

1. Goryachkin, Yu.N. and Kosyan, R.D., 2020. Formation of a New Island of the Coast of Crimea. Oceanology, 60(2), pp. 286-292. https://doi.org/10.1134/S0001437020020034

2. Ivanov, V.A., Goryachkin, Yu.N., Udovic, V.F., Kharitonova, L.V. and Shutov, S.A., 2012. Current State and Evolution of the Bakai Spit. In: MHI, 2012. Ekologicheskaya Bezopasnost' Pribrezhnykh i Shel'fovykh Zon i Kompleksnoe Ispol'zovanie Resursov Shel'fa [Ecological Safety of Coastal and Shelf Zones and Comprehensive Use of Shelf Resources]. Sevastopol: ECOSI-Gidrofizika. Iss. 26(1), pp. 8-15 (in Russian).

3. Kharitonova, L.V., Ivancha, E.V. and Alekseev, D.V., 2015. Effect of Storm Surges and Wind Waves on Morphodynamic Processes in the Bakalskaya Spit Region. Physical Oceanography, (1), pp. 73-84. doi:10.22449/1573-160X-2015-1-73-84

4. Fomin, V.V., Alekseev, D.V. and Kharitonova, L.V., 2013. [Modeling the the Bakalskaya Spit Morphodynamics]. In: MHI, 2013. Ekologicheskaya Bezopasnost' Pribrezhnykh i Shel'fovykh Zon i Kompleksnoe Ispol'zovanie Resursov Shel'fa [Ecological Safety of Coastal and Shelf Zones and Comprehensive Use of Shelf Resources]. Sevastopol: ECOSIGidrofizika. Iss. 27, pp. 374-380 (in Russian).

5. Goryashkin, Yu.N. and Repetin, L.N., 2009. Storm Wind and Wave Regime near the Black Sea Coast of Crimea. In: MHI, 2009. Ekologicheskaya Bezopasnost' Pribrezhnykh i Shel'fovykh Zon i Kompleksnoe Ispol'zovanie Resursov Shel'fa [Ecological Safety of Coastal and Shelf Zones and Comprehensive Use of Shelf Resources]. Sevastopol: ECOSIGidrofizika. Iss. 19, pp. 56-69 (in Russian). 
6. Goryachkin, Y.N., Udovik, V.F. and Kharitonova, L.V., 2011. Estimations of the Parameters of the Flux of Sediments near the West Coast of the Bakal'skaya Spit under the Conditions of Heavy Storms in 2007. Physical Oceanography, 20(5), 356. https://doi.org/10.1007/s11110011-9091-9

7. Naumova, V.A., Evstigneev, M.P., Evstigneev, V.P. and Ljubarec, E.P., 2010. Wind and Wave Forming Conditions in Azov-Black Sea Coast Region. In: UHMI, 2010. Naukovi Pratsi Ukrainskoho Hidrometeorolohichnoho Instytutu [Scientific Works of the Ukrainian Hydrometeorological Institute]. Kiev: UHMI. Iss. 259, pp. 263-283 (in Russian).

8. Kharitonova, L.V. and Fomin, V.V., 2012. Statistical Characteristics of Wind Waves in the Coastal Area of the Western Crimea according to Retrospective Estimation during 1979-2010. In: MHI, 2012. Ekologicheskaya Bezopasnost' Pribrezhnykh i Shel'fovykh Zon i Kompleksnoe Ispol'zovanie Resursov Shel'fa [Ecological Safety of Coastal and Shelf Zones and Comprehensive Use of Shelf Resources]. Sevastopol: ECOSI-Gidrofizika. Iss. 26(1), pp. 2433 (in Russian).

9. Divinsky, B.V., 2018. Hydrodynamic Water Conditions in the Bakalskaya Spit Area. Ekologicheskaya Bezopasnost' Pribrezhnoy i Shel'fovoy Zon Morya = Ecological Safety of Coastal and Shelf Zones of Sea, (4), pp. 31-39. doi:10.22449/2413-5577-2018-4-31-39 (in Russian).

10. Divinsky, B.V. and Kosyan, R.D., 2020. Influence of the Climatic Variations in the Wind Waves Parameters on the Alongshore Sediment Transport. Oceanologia, 62(2), pp. 190-199. doi:10.1016/j.oceano.2019.11.002

11. Rudnev, V.I., 2018. Peculiarities of the Bottom Relief of the Bakalskaya Spit Foreshore. Ekologicheskaya Bezopasnost' Pribrezhnoy i Shel'fovoy Zon Morya = Ecological Safety of Coastal and Shelf Zones of Sea, (4), pp. 15-21. doi:10.22449/2413-5577-2018-4-15-21 (in Russian).

12. Rudnev, V.I., Divinskiy, B.V. and Kosyan, R.D., 2020. Changes in Topography of the Coastal Zone of the Bakalskaya Spit from 2018 to 2019. Ekologicheskaya Bezopasnost' Pribrezhnoy i Shel'fovoy Zon Morya = Ecological Safety of Coastal and Shelf Zones of Sea, (1), pp. 22-35. doi:10.22449/2413-5577-2020-1-22-35 (in Russian).

13. Divinsky, B.V. and Kosyan, R.D., 2017. Spatiotemporal Variability of the Black Sea Wave Climate in the Last 37 Years. Continental Shelf Research, 136, pp.1-19. http://dx.doi.org/10.1016/j.csr.2017.01.008

14. Divinsky, B. and Kosyan, R., 2018. Parameters of Wind Seas and Swell in the Black Sea Based on Numerical Modeling. Oceanologia, 60(3), pp. 277-287. https://doi.org/10.1016/j.oceano.2017.11.006

15. Klecka, W.R., 1980. Discriminant Analysis. SAGE Publications, Inc. https://dx.doi.org/10.4135/9781412983938

About the authors:

Boris V. Divinsky, Leading Research Associate, Laboratory of Geology and Lithodynamics, Shirshov Institute of Oceanology, Russian Academy of Sciences (36, Nahimovskiy prospekt, Moscow, Russia, 11799), Ph. D., ORCID ID: 0000-0002-2452-1922, ResearcherID: C-7262-2014, divin@ocean.ru

Ruben D. Kosyan, Head of the Laboratory of Geology and Lithodynamics, Shirshov Institute of Oceanology, Russian Academy of Sciences (36, Nahimovskiy prospekt, Moscow, Russia, 11799), Dr. Sci. (Geography), Professor, ResearcherID: C-5154-2014, rkosyan@hotmail.com 
Contribution of the co-authors:

Boris V. Divinsky - formulation of the goals and objectives of the study; analysis of materials on the research topic; correction of the mathematical model and carrying out calculations; processing and description of research results; preparation of the initial version of the text

Ruben D. Kosyan - initiation of research; general scientific management of research; analysis and generalization of research results; revision of the text

All the authors have read and approved the final manuscript.

The authors declare that they have no conflict of interest. 